\title{
Study on dynamic characteristics of silo-stock-foundation interaction system under seismic load
}

https://doi.org/10.1515/phys-2018-0060

Received May 15, 2018; accepted June 8, 2018

\begin{abstract}
In order to reveal the dynamic response mechanism of silo-storage-foundation system under seismic wave loading, the silo is simplified as a thin-walled cylindrical shell structure with fixed bottom and free upper part. Considering geometric nonlinearity, dynamic elastic modulus, damping and other factors, the nonlinear vibration differential equations of the silo under dynamic loading are established. The Galerkin method is used to discretize the vibration differential equations, and the definite conditions with solution ideas are given. Subsequently, the dynamic action system of tube supported reinforced concrete silos is studied by using the shaking table test method. The similarity theory of silo model test is constructed, and the experimental model of the silo storage foundation interaction system with the geometric ratio of 1:20 is established, where three seismic waves in the suitable engineering background are selected to carry out the shaking table test. The acceleration peak value at different heights of the model is measured, and the dynamic amplification factor of the silo model along the height direction is studied under different seismic intensity and different material condition. The seismic performance of the prototype structure is studied, which provides the theoretical basis and practical guidance for the design of silo system and the operation and management of silos.
\end{abstract}

Keywords: silo-stock-foundation system, shaking table test, dynamic magnification coefficient, dynamic characteristics.

PACS: 05.90.+m, 62.30.+d

\footnotetext{
Li Shuwei: Northeastern University, Shenyang, Liaoning province, China and China Energy Engineering Group CO., Ltd., Beijing, China Zhao Wen: Northeastern University, Shenyang, Liaoning province, China

*Corresponding Author: Guo Zhiyu: China Energy Construction Group Heilongjiang Electric Power Design Institute Co., Ltd., Haerbin, Heilongjiang province, China, E-mail: 970222803@qq.com
}

\section{Introduction}

With the advantage of simple operation, environmental protection, land saving, less loss and the like, Silo structure has become a universal structure widely used in industry, enterprises and transportation departments [1-3]. At present, domestic and foreign scholars have done a lot of theoretical and experimental research on static characteristics of silo structure [4-7]. Pieraccini et al. [8]studied the buckling of a silo with different structure types caused by the impact load during the storage loading and unloading process, and several different models were used to carry out experimental research and numerical simulation analysis. K Knebel et al. [9] studied the bending buckling problem of full bunker. The results showed that the compressive stress of bulk can greatly increase the buckling critical load of thin shell wall. C.Butenweg et al. [10] compared two methods of silo force analysis under static and dynamic equivalent load. The interaction between silos and storage materials had been considered in the analysis. Through geometric nonlinear analysis, Ji [11] researched systematically on the influence of cylindrical support steel silo's geometric parameters such as diameter and thickness of columns, steel stall, column height, radius and ratio of pillar to width on structural stability and strength. On the basis of the interaction of silos and bulk materials, the dynamic behavior of the silo system under the earthquake action is evaluated by Durmuş, A. et al. [12], and a simplified method for the approximation of the finite element model is proposed for the analysis. The results show that the method has high accuracy. However, most of these studies only relate to the engineering mechanical properties of a single silo structure[13-16], lack of the research on silo storage foundation interaction system under dynamic load. and the related mechanism is not clear, but seismic action is one of the main factors that cause instability and failure of silo structure [17-19]. Therefore, it is of great practical significance to study the dynamic characteristics of silo storage foundation interaction system under earthquake load. 
In this paper, the silo-storage-foundation system is taken as the research object. Through the Shaking table simulation test, the dynamic characteristics of the silostorage-foundation system under different storage conditions are tested, The seismic design of the existing silostorage-foundation system is carried out, and the effectiveness of the aseismic device is verified by numerical calculation.The research results can provide some theoretical basis and reference value for the design of safe operation of silo structures under special conditions.

\section{Basic equations of dynamic model}

Silo storage foundation interaction system can be regarded as a composite thin-walled cylindrical shell with one end fixed and another end free. In the role of external periodic load changes, the cylindrical shell diagram and its stratification shown in Figure 1 cylindrical shell in the movement process will have a displacement of each point in the cylindrical coordinate system with $u, v, w$ and the three displacement components are simultaneously functions of the spatial coordinates $x, \theta, r$ and time $t$.

\subsection{Geometric equation}

The strain component at any point of a thin-walled cylindrical shell has the following relationship with the midplane strain, mid-plane bending deflection, and midplane distortion:

$$
\begin{aligned}
\varepsilon_{x} & =\varepsilon_{x}^{0}+z \chi_{x} \\
\varepsilon_{\theta} & =\varepsilon_{\theta}^{0}+z \chi_{\theta} \\
\varepsilon_{x \theta} & =\varepsilon_{x \theta}^{0}+z \chi_{x \theta}
\end{aligned}
$$

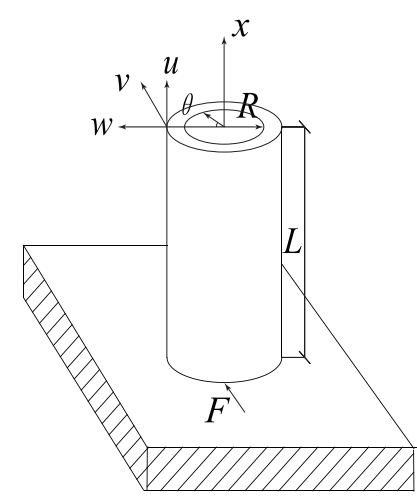

Figure 1: Model of a circular cylindrical shell
In the formula: $\varepsilon_{\chi}^{0}, \varepsilon_{\theta}^{0}, \varepsilon_{x \theta}^{0}$ are the film strain components of the middle curve, $\chi_{x}, \chi_{\theta}$ is the mid-plane bending deflection, $\chi_{x \theta}$ is the mid-plane twist, and $z$ is the distance from any point on the shell to the middle.

According to the Donnell shell theory [20,21], the firstorder derivative nonlinearity of the normal deflection is taken into account in the relationship between the midsurface strain and the mid-surface displacement.

$$
\begin{aligned}
\varepsilon_{x}^{0} & =\frac{\partial u}{\partial x}+\frac{1}{2}\left(\frac{\partial w}{\partial x}\right)^{2} \\
\varepsilon_{\theta}^{0} & =\frac{1}{R}\left(\frac{\partial v}{\partial \theta}+w\right)+\frac{1}{2}\left(\frac{\partial w}{R \partial \theta}\right)^{2} \\
\varepsilon_{x \theta}^{0} & =\frac{\partial v}{\partial x}+\frac{1}{R} \frac{\partial u}{\partial \theta}+\frac{\partial w}{\partial x} \frac{1}{R} \frac{\partial w}{\partial \theta}
\end{aligned}
$$

Of these the underlined items represent the nonlinear terms.

In Donnell's nonlinear shell theory $[16,20]$, the midplane bending strain component remains linear [15]:

$$
\begin{aligned}
\chi_{x} & =-\frac{\partial^{2} w}{\partial x^{2}} \\
\chi_{\theta} & =-\frac{1}{R^{2}} \frac{\partial^{2} w}{\partial \theta^{2}} \\
\chi_{x \theta} & =-\frac{2}{R} \frac{\partial^{2} w}{\partial x \partial \theta}
\end{aligned}
$$

\subsection{Physical equations}

Taking into account the elastic modulus of the composite material with the vibration frequency changes, the two have the following relationship:

$$
\begin{gathered}
E_{1}(\omega)=E_{2}(\omega)=E_{3}(\omega)=2.5751 \times 10^{9} \\
+\frac{2 \times 3.2283 \times 10^{12}}{\pi} \times\left[\frac{238.62}{4 \times(\omega / 2 \pi-0.46787)^{2}+238.62^{2}}\right] \\
E_{4}(\omega)=5.04289 \times 10^{8}+9.2387 \times 10^{9} \times e^{-0.0064 \omega / 2 \pi}
\end{gathered}
$$

Physical equation of layer $K$ of isotropic laminated shell:

$$
\left[\begin{array}{c}
\sigma_{x} \\
\sigma_{\theta} \\
\tau_{x \theta}
\end{array}\right]_{k}=\left[\begin{array}{ccc}
Q_{11} & Q_{12} & 0 \\
Q_{21} & Q_{22} & 0 \\
0 & 0 & Q_{66}
\end{array}\right]_{k}\left[\begin{array}{c}
\varepsilon_{x} \\
\varepsilon_{\theta} \\
\varepsilon_{x \theta}
\end{array}\right]_{k}
$$

Among them $Q_{i}^{j}$ is reduced stiffness matrix, the elements given by:

$$
\begin{gathered}
\left(Q_{11}\right)_{k}=\left(Q_{22}\right)_{k}=E_{k}(\omega) /\left(1-\mu_{k}^{2}\right) \\
\left(Q_{12}\right)_{k}=\left(Q_{21}\right)_{k}=E_{k}(\omega) \cdot \mu_{k} /\left(1-\mu_{k}^{2}\right)
\end{gathered}
$$




$$
\left(Q_{66}\right)_{k}=E_{k}(\omega) / 2\left(1+\mu_{k}\right)
$$

Among them: $E_{k}(\omega)$ is k-th elastic modulus, $\mu_{k}$ is k-th layer of Poisson's ratio.

\subsection{Dynamic balance equation}

According to the principle of D'Alembert, the dynamic equilibrium equation of a laminated composite cylindrical shell can be established:

$$
\begin{gathered}
\frac{\partial N_{x}}{\partial x}+\frac{1}{R} \frac{\partial N_{x \theta}}{\partial \theta}-\sum_{k=1}^{4} \rho_{k}\left(z_{k}-z_{k-1}\right) \frac{\partial^{2} u}{\partial t^{2}}=0 \\
\frac{1}{R} \frac{\partial N_{\theta}}{\partial \theta}+\frac{\partial N_{x \theta}}{\partial x}+\frac{Q_{\theta}}{R}-\sum_{k=1}^{4} \rho_{k}\left(z_{k}-z_{k-1}\right) \frac{\partial^{2} v}{\partial t^{2}}=0 \\
\frac{\partial Q_{x}}{\partial x}+\frac{1}{R} \frac{\partial Q_{\theta}}{\partial \theta}-\frac{1}{R} N_{\theta}+N_{x} \frac{\partial^{2} w}{\partial x^{2}}+\frac{N_{\theta}}{R^{2}} \frac{\partial^{2} w}{\partial \theta^{2}}+\frac{2 N_{x \theta}}{R} \frac{\partial^{2} w}{\partial x \partial \theta} \\
-\sum_{k=1}^{4} \rho_{k}\left(z_{k}-z_{k-1}\right) \frac{\partial^{2} w}{\partial t^{2}}-c \frac{\partial w}{\partial t}-q_{r}=0
\end{gathered}
$$

Among them:

$$
\begin{aligned}
& Q_{x}=\frac{1}{R} \frac{\partial M_{x \theta}}{\partial \theta}+\frac{\partial M_{x}}{\partial x} \\
& Q_{\theta}=\frac{\partial M_{x \theta}}{\partial x}+\frac{1}{R} \frac{\partial M_{\theta}}{\partial \theta}
\end{aligned}
$$

\section{Model test of silo-storage-foundation dynamic interaction system}

\subsection{Project examples}

Shenyang Jinshan Thermal Power "To the small" heating project is located in Sujiatun District, Shenyang City Hunhe South Bank. Its coal handling system needs 5 silos of 10000 tons, with a diameter of $22 \mathrm{~m}$ and a height of $39.730 \mathrm{~m}$. According to the specifications of the proposed silo construction project for the warehouse. Coal is lignite, bulk density by $10 \mathrm{kN} / \mathrm{m}^{3}$. Seismic fortification intensity of 7 degrees, the design of the basic seismic acceleration $0.10 \mathrm{~g}$, Seismic structural measures at 7 degrees fortification, the first group of seismic sub-group design, seismic grade two; structural safety rating of two; fire rating of two; silo foundation design grade $B$, design life of 50 years. The base bearing layer is medium sand, and the silo wall is made of reinforced concrete.

\subsection{Test materials}

The model test silo material used particulate concrete and galvanized wire mesh instead of the reinforced concrete material of the prototype silo. In order to simulate the interaction between the soil and the structure, a foundation soil model was prepared using spun yarn, calcium carbonate, and gypsum to ensure a reliable connection between the model structure and the vibration table. The configuration of the foundation soil was similar to the elastic modulus and density parameters of the original soil. The original storage was lignite, and similar fine-grained coal particles were used as similar materials for the storage.

\subsection{Model test similarity criteria}

The similarity ratio of the experimental model is selected as 1:20, the total height of the prototype is $40 \mathrm{~m}$, and the total height of the model is $2.0 \mathrm{~m}$. During the construction of the model, three particle concrete cubic test blocks $(70.7 \mathrm{~mm} \times 70.7 \mathrm{~mm} \times 70.7 \mathrm{~mm})$ and three prism test blocks (100 $\mathrm{mm} \times 100 \mathrm{~mm} \times 300 \mathrm{~mm}$ ) were simultaneously produced. After 28 days of curing, material performance tests were conducted to test the actual compressive strength and elastic modulus of the particulate concrete material that determine the model similarity coefficient.

The test measured the elastic modulus of the microparticle concrete was $9.33 \mathrm{GPa}$, the bulk density of the micro-particle concrete was $24.9 \mathrm{kN} / \mathrm{m}^{3}$, and the geometric similarity coefficient was 1:20. Based on these three parameters, similarity coefficients of other major parameters can be derived based on the similarity criteria. The following relationship can be derived:

$$
\begin{aligned}
\alpha_{t} & =\alpha_{L} \sqrt{\frac{\alpha_{\gamma}}{\alpha_{E}}} \\
\alpha_{a} & =\frac{\alpha_{E}}{\alpha_{\gamma} \alpha_{L}} \\
\alpha_{v} & =\sqrt{\frac{\alpha_{E}}{\alpha_{\gamma}}} \\
\alpha_{\omega} & =\frac{1}{\alpha_{L}} \sqrt{\frac{\alpha_{E}}{\alpha_{\gamma}}}
\end{aligned}
$$

Finally, the model similarity coefficient is determined as shown in the Table 1:

Table 1: Model dynamic similarity coefficient table

length Weight Elastic Modulus stress acceleration speed time frequency

\begin{tabular}{llllllll}
\hline $1 / 20$ & 1 & 0.33 & 0.33 & 6.6 & 0.57 & 0.087 & 11.4
\end{tabular}




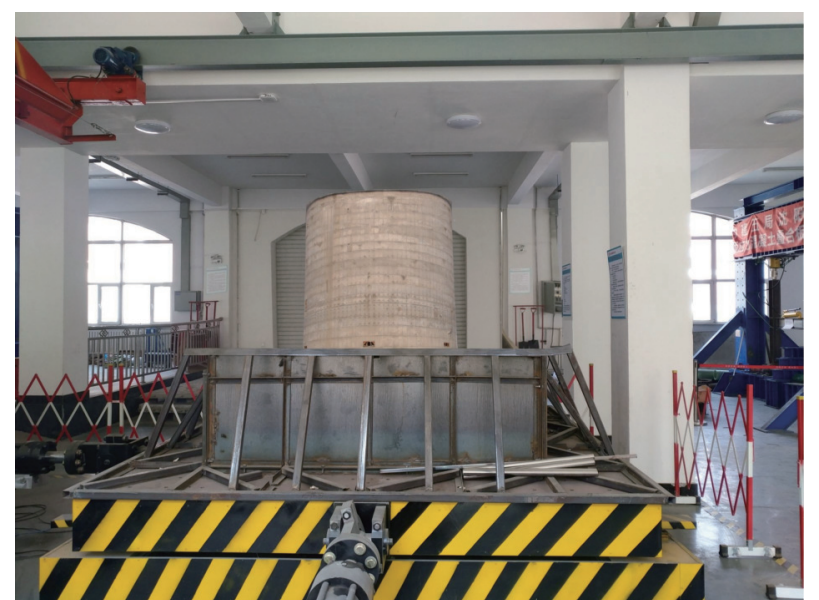

Figure 2: The text model and equipment

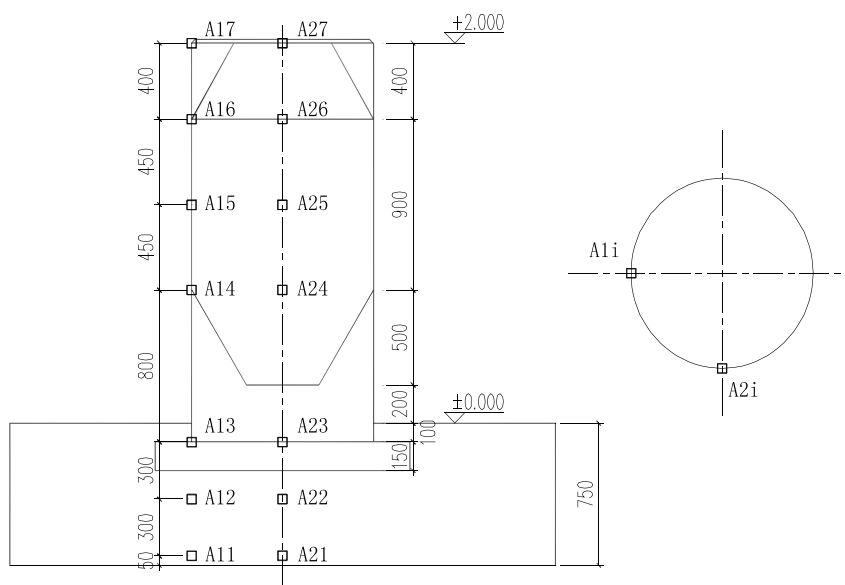

Figure 3: Accelerometer layout

\subsection{Test equipment}

The vibration table used in this test is a $3 \mathrm{~m} \times 3 \mathrm{~m}$ electrohydraulic servo shaker with a holding time of 5 minutes, Equipped with GS2000 servo controller, digitally controlled dynamic data acquisition system. Text model and equipment shown in Figure 2.

The test and measurement instruments used in this test are mainly acceleration sensors. According to the mechanical characteristics of silo-storage-foundation interaction, a total of 14 accelerometers are arranged in the key parts of the structure, as shown in Figure 3.

\subsection{Selection and adjustment of seismic waves}

The three factors of ground motion are frequency, amplitude and duration. When the seismic waves are selected, the characteristics of the selected seismic waves should be met according to the category of the building site, even if the main period of the design of the earthquake is close to the excellent period of the site. The original site category is class II, and the seismic fortification intensity is 7 degrees.

Considering the comprehensive consideration, 2 natural seismic waves (EL Centro wave and Lanzhou wave) and a artificial waves are selected as experimental input seismic waves. The seismic time history curves and spectral curves are shown in Figure 4.

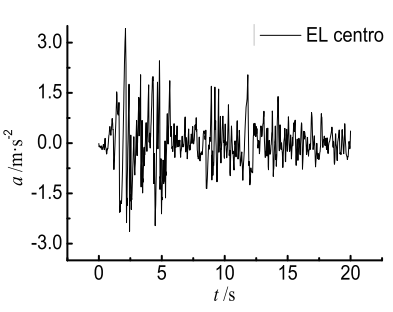

(a) EL centro wave seismic time history curves

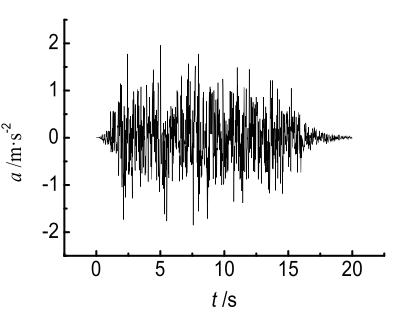

(c) EL centro wave spectrum curve

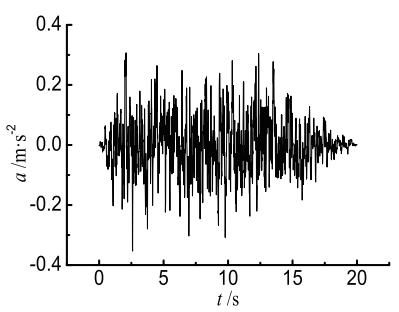

(e) EL centro wave spectrum curve

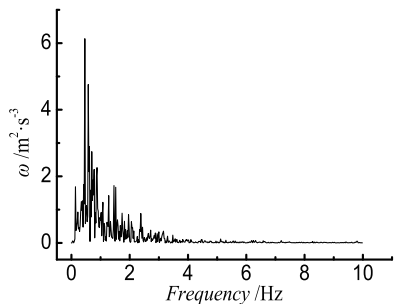

(b) EL centro wave spectrum curve

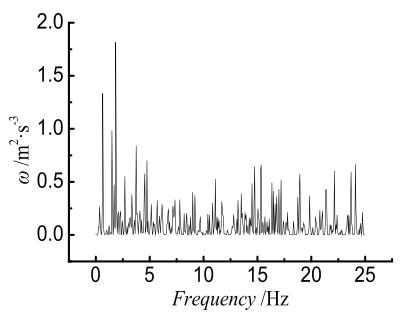

(d) EL centro wave spectrum curve

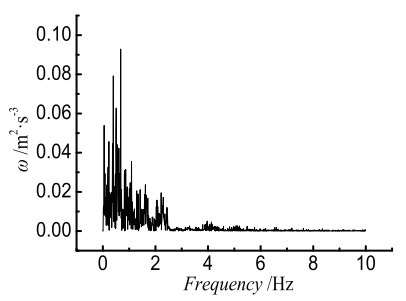

(f) EL centro wave spectrum curve
Figure 4: Time history curve and spectrum curve of seismic wave

After selecting the actual seismic wave, the amplitude of the selected seismic wave must also be adjusted. According to the regulations, the maximum value of ground motion acceleration with 7 degrees frequently earthquake is $35 \mathrm{~cm} / \mathrm{s}^{2}$, the 7 degree fortification earthquake is $100 \mathrm{~cm} / \mathrm{s}^{2}$ and the 7 degree rare earthquake is $220 \mathrm{~cm} / \mathrm{s}^{2}$. 


\subsection{Test program}

In this experiment, a multiple loading scheme is used to input two-way horizontal seismic waves at each loading. The acceleration ratio of bidirectional input seismic waves is $X: Y=1: 0.8$. Designed three conditions of empty storage, $1 / 2$ storage and full storage. The peak acceleration of each load was gradually increased, corresponding to 7 degrees frequently earthquake, 7 degree fortification earthquake and 7 degree rare earthquake three seismic levels.

\subsection{Model test results}

The maximum measured acceleration value of the acceleration sensor in the base position of the silo model is taken as the reference value, and the magnification coefficient of the model under the same working condition can be obtained by comparing the measured maximum value of the acceleration sensor at the different heights of the model.

The change law of structural dynamic amplification factor is relatively complex, which is related to the characteristics of the model structure, the development of inelastic deformation, and the input seismic spectrum characteristics of the vibratory table, which can reflect the changes and destruction of the dynamic response of the model. In order to investigate the changes of the model's dynamic amplification along its height direction, the change law of the acceleration magnification factor along the height direction of the model is analyzed. The acceleration peaks and the changing trend of dynamic amplification factor under various operating conditions are shown in Figures $5-7$.
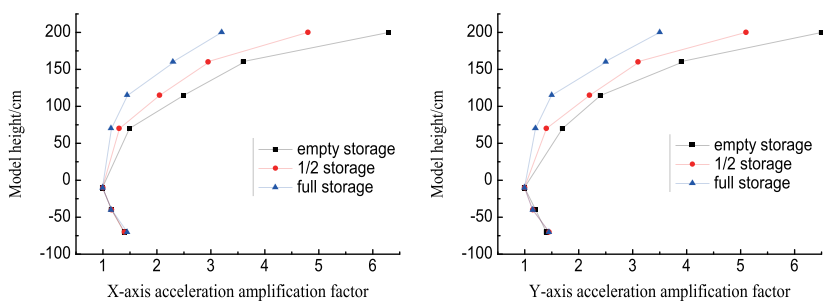

Figure 5: Dynamic magnification coefficient of the 7 degrees frequently earthquake

\section{Conclusions}

(1) The peak acceleration measured from the foundation model shows that the input seismic load is reduced in
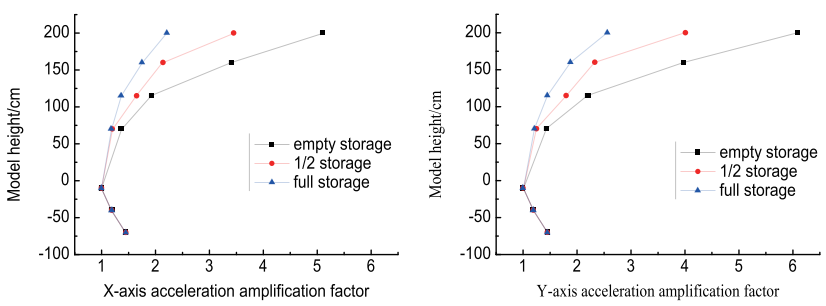

Figure 6: Dynamic magnification coefficient of the 7 degree fortification earthquake
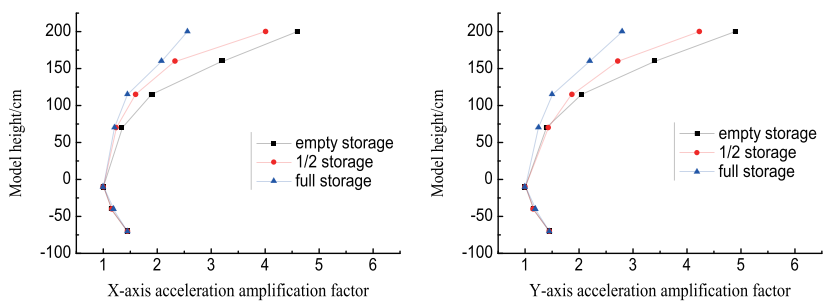

Figure 7: Dynamic magnification coefficient of the 7 degree rare earthquake

the foundation, and the acceleration peak to the base surface is reduced to about $65 \% \sim 75 \%$ of the input peak. It is necessary to consider the interaction of silo foundation and consider the interaction of silo foundation, which is more suitable for engineering practice.

(2) Under the action of seismic intensity at the design levels, the peak acceleration of the model gradually enlarges from the base to the top, and the maximum acceleration response occurs at the top of the model structure, indicating that the model structure is the first mode of vibration. At the same time, the top of the top has certain whiplash effect, which indicates the existence of higher mode shapes.

(3) Under the condition of the same material, the acceleration magnification coefficient decreases with the increase of seismic intensity, indicating that the structure gradually enters the nonlinear stage, and the stiffness of the structure gradually decreases. Under the action of 7 degree rare earthquake intensity wave, the acceleration magnification coefficient has a larger decrease, indicating that the damage inside the silo model begins to occur.

(4) With the increase of storage materials, the acceleration amplification coefficient of the model clearly decreases. The $\mathrm{X}$ acceleration magnification factor of the 7 degree rare warehouse top is 4.60, 4.01 and 2.56 respectively in empty storage, $1 / 2$ storage and full storage. This indicates that the movement of the storage material is not synchronous with the movement of the 
silo body, and there is phase difference. The interaction between the silo and the storage tank plays a role of damping energy dissipation for the model structure.

Acknowledgement: This research was substantially funded by the National Natural Science Foundation of China (51504123).

\section{References}

[1] Xuecheng J.X.D., The Physical Model of Pile-Soil and StructurePile-Soil Interaction System, J. Vibr. Eng., 1993, 2, 005.

[2] Zongda J.X.Y., Earthquake Response Analysis of Building Foundation Building Interaction System, J. Vibr. Eng., 1998, 1, 23-28.

[3] Wójcik M., Sondej M., Rejowski K., Tejchman J., Full-scale experiments on wheat flowin steel silo composed of corrugated walls and columns, Powder Techn., 2017, 311, 537-555.

[4] Ayuga F., Some unresolved problems in the design of steel cylindrical silos, Int. Conf. on structures and granular solids-from scientific principles to engineering applications, The Royal Society of Edinburgh, Scotland, UK, 2008, 6, 123-133.

[5] Toma A.E., Atanasiu G.M., Specific Behavior of Circular Metal Silo, Advanced Engineering Forum, Trans Tech Publications, 2017, 21, 65-72.

[6] Tu P., Vimonsatit V., Silo quaking of iron ore train load out bin-A time-varying mass structural dynamic problem, Adv. Powder Techn., 2017, 28(11), 3014-3025.

[7] Yu X., Raeesi A., Ghaednia H., Heydariha J., Das S., Xie S., Behavior of a Large Steel Field Silo Structure Subject to Grain Loading, J. Perf. Constr. Fac., 2017, 31(5), 401-407.

[8] Pieraccini L., Silvestri S., Trombetti T., Refinements to the Silvestri's theory for the evaluation of the seismic actions in flatbottom silos containing grain-like material, Bulletin Earthquake Eng., 2015, 13(11), 3493-3525.

[9] Knebel K., Schweizerhof K., Buckling of cylindrical shells containing granular solids, Thin-walled struct., 1995, 23, 295-312.

[10] Butenweg C., Rosin J., Holler S., Analysis of Cylindrical Granular Material Silos under Seismic Excitation, Buildings, 2017, 7(3), 61-66.
[11] Yu J., Study on stability behavior and strength of column supported steel silos with engaged column, 2005, Zhejiang University, (in Chinese)

[12] Durmus A., Livaoglu R., A simplified 3 DOF model of A FEM model for seismic analysis of a silo containing elastic material accounting for soil-structure interaction, Soil Dynam. Earthquake Eng., 2015, 77, 1-14.

[13] Wang X., Yang Z., Shu X., Feng J., The static contact statuses between granularmaterials and flat-bottomed steel silos, Powder Techn., 2013, 35, 1053-1059.

[14] Kanyilmaz A., Castiglioni C.A., Reducing the seismic vulnerability of existing elevated silos by means of base isolation devices, Eng. Struct., 2017, 143, 477-497.

[15] Llibre J., Centers: their integrability and relations with the divergence J. Applied Mathematics and Nonlinear Sciences, 2016,1(1), 79-86.

[16] Khellat F., Khormizi M.B., A global solution for a reaction diffusion equation on bounded domains, Appl. Math. Nonlin. Sci., 2018, 3(1), 15-22.

[17] Livaoglu R., Durmus A., A simplified approximation for seis- mic analysis of silo-bulk material system, Bulletin of Earthquake Eng., 2016, 14(3), 863-887.

[18] Kermiche S., Boussaid O., Redjel B., Amirat A., FEM investigation of concrete silos damaged and reinforced externally with CFRP, Mech. Industry, 2017, 18(6), 609.

[19] Palermo M., Stefano S., Trombetti T., On the Fundamental Periods of Vibration of Flat-Bottom Ground-Supported Circular Silos containing Gran-like Material, Procedia Eng., 2017, 199, 248253.

[20] Simón C.B., López J.C.C., Altuzar L.V., Micó R.J.V., Mean square calculus and random linear fractional differential equations: Theory and applications, Appl. Math. Nonlin. Sci., 2017, 2(2), 317-328.

[21] Dewasurendra M., Vajravelu K., On the Method of Inverse Mapping for Solutions of Coupled Systems of Nonlinear Differential Equations Arising in Nanofluid Flow, Heat and Mass Transfer, Appl. Math. Nonlin. Sci., 2018, 3(1), 1-14. 